\title{
EFEK HARDINESS TERHADAP PERILAKU MENCONTEK MELALUI EFIKASI DIRI SISWA SEKOLAH MENENGAH ATAS
}

\author{
Widya Khairunissa Hidayat, Herlina, Lira Fessia Damaianti
}

\author{
Departemen Psikologi \\ Universitas Pendidikan Indonesia \\ widyakh19@gmail.com,herlinahasan_psi@upi.edu,lfdamaianti@gmail.com
}

\begin{abstract}
This study aims to find out the influence of hardiness personality on cheating behavior through self-efficacy. Sample of study consist of 319 students of a high school. The instrument used is hardiness scale from Creed, Conlon, and Dhaliwal (2013), cheating behavior questionnaire which is adopted from Saddam (2016), and self-efficacy questionnaire from Schwarzel and Jarusalem (1995). This study use quantitative method with path analysis to find out cause-effect relation and involve self-efficacy variable as mediator variable. The results of study show that: 1) There is significant negative influence of hardiness personality on cheating behavior; 2) There is significant influence of hardiness personality on self-efficacy; 3) Self-efficacy variable statistically can become significant mediator variable for hardiness personality toward cehating behavior. Therefore, hardiness personality becocme one contribution to influence students' behavior in doing all tasks assigned and self-efficacy possessed also can contribute to students to be confident in finishing the tasks assigned at school.
\end{abstract}

Keywords: hardiness, cheating behavior, self-efficacy, Senior High School students

\begin{abstract}
Abstrak
Penelitian ini bertujuan untuk mengetahui pengaruh kepribadian hardiness terhadap perilaku mencontek melalui efikasi diri. Sampel penelitian terdiri dari 319 siswa-siswi SMA. Instrumen yang digunakan adalah Hardiness scale dari Creed, Conlon, dan Dhaliwal (2013), kuesioner perilaku mencontek yang diadopsi dari Wijaya (2016), dan kuesioner efikasi diri dari Schwarzel dan Jarusalem (1995). Metode penelitian yang digunakan adalah kuantitatif dengan path analysis untuk mengetahui hubungan sebab-akibat serta melibatkan variabel efikasi diri sebagai variabel mediator. Hasil penelitan meunjukkan: 1) Terdapat pengaruh yang signifikan dari pengaruh kepribadian hardiness terhadap perilaku mencontek dengan berpengaruh secara negatif; 2) Terdapat pengaruh yang signifikan dari pengaruh kepribadian hardiness terhadap efikasi diri; 3) Variabel efikasi diri secara statistik dapat signifikan menjadi variabel mediator bagi kepribadian hardiness terhadap perilaku mencontek. Sehingga kepribadian hardiness menjadi salah satu sumbangsih untuk mempengaruhi perilaku siswa-siswi di sekolah dalam mengerjakan segala tugas yang dimiliki dan efikasi diri atau keyakainan yang dimiliki juga dapat menjadi sumbangsih siswa untuk yakin menyelesaikan tugas yang diterima di sekolah.
\end{abstract}

Kata kunci: hardiness, perilaku mencontek, efikasi diri, siswa SMA 


\section{PENDAHULUAN}

Pada dasarnya seorang siswa memiliki tugas-tugas yang harus diselesaikan. Namun tugas tersebut tidak selalu mudah. Dalam menghadapi tugas menantang tersebut, siswa di sekolah menengah atas lebih cenderung melakukan perilaku mencontek dibandingkan dengan siswa di sekolah dasar (Anderman \& Mudrock, 2007). Secara garis besar perilaku mencontek disebabkan oleh dua faktor, yaitu faktor eksternal dan faktor internal. Faktor eksternal dalam perilaku mencontek terdiri dari tekanan yang ada pada teman sebaya, tekanan dari orang tua, peraturan sekolah yang kurang jelas, sikap guru yang kurang tegas terhadap siswa yang melakukan tindakan mencontek, sedangkan faktor internal dalam perilaku mencontek terdiri dari efikasi diri yang rendah, kemampuan akademik yang rendah, manajemen waktu, dan prokrastinasi (Hartanto, 2012).

Perilaku mencontek juga biasa disebut dengan academic cheating atau kecurangan akademik, hal tersebut merupakan salah satu bentuk ketidakjujuran (Kumalasari, 2015). Kejujuran, motivasi, dan self control terdapat pada kepribadian. Kepribadian merupakan karakteristik khas yang dimiliki oleh seseorang. Salah satu tipe kepribadian adalah hardiness. Hardiness merupakan karakteristik kepribadian yang memiliki komponen utama yaitu commitment, control, dan challenge (Kobasa et al., 1982). Maddi (2013) mengungkapkan bahwa hardiness adalah karakteristik kepribadian yang membuat individu menjadi lebih kuat, tahan, stabil, dan optimis dalam menghadapi stres dan mengurangi efek stres yang dialami, hardiness juga akan memandang hidup sebagai sesuatu yang harus dihadapi. Kepribadian hardiness dapat diperoleh melalui pembelajaran (Maddi, 2006), berpengaruh positif pada bidang sekolah (Maddi, Harvey, Khoshaba, Fazel, \& Resurreccion, 2009) serta dibentuk oleh tiga komponen dasar, yaitu commitment, control, dan challenge (Kobasa, 1979).

Menurut Hystad (dalam Kusmaningtyas, 2015) seseorang dengan kepribadian hardiness yang tinggi akan percaya bahwa dirinya dapat mengontrol setiap peristiwa yang mengandung stres dan memiliki persepsi sebagai peristiwa yang positif dan konstruktif sehingga menjadi tantangan dan dapat dijadikan suatu pelajaran di dalam kehidupan. Hardiness dapat membantu siswa untuk kuat, tahan, stabil, optimis dalam menghadapi berbagai tugas. Kontrol diri yang baik akan mampu mengontrol siswa agar tidak melakukan perilaku mencontek, komitmen yang baik membuat siswa memandang berbohong adalah perbuatan curang (Vijayalakshmi et al., 2016).

Penelitian yang dilakukan oleh Eschleman, tahun 2010 mengungkapkan bahwa hardiness membuat seseorang menghadapi berbagai kesulitan sebagai tantangan bukan ancaman. Siswa yang menerima kesulitan sebagai tantangan akan mengerjakan tugas dengan penuh keyakinan, siswa yang menganggap kesulitan sebagai ancaman akan 
mencari jalan lain untuk menyelesaikan tugas. Disamping itu, seseorang dengan hardiness yang rendah akan lebih menyukai untuk menarik diri pada keadaan dan merasa bahwa hal tersebut sebagai ancaman. (Kardum, Hudek-Knežević, \& Krapić, 2012).

Keyakinan seseorang untuk dapat menyelesaikan suatu tugas disebut sebagai efikasi diri (Bandura, 2009). Efikasi diri yang tinggi akan membuat siswa memiliki keyakinan untuk menyelesaikan tugas. Efikasi diri memiliki tiga dimensi yaitu level, strength, dan generality (Bandura, 2009). Level merupakan cara pandang seseorang terhadap taraf kesulitan yang dihadapi, strength merupakan kekuatan untuk menghadapi kesulitan, dan generality merupakan konsep yang dapat diletakkan pada segala situasi bahwa dirinya memiliki keyakinan untuk dapat menyelesaikan suatu tujuan.

Berdasarkan pemaparan di atas, peneliti memandang bahwa kepribadian hardiness dan efikasi diri yang tinggi membuat siswa memiliki ketahanan dalam menghadapi tugas dan keyakinan untuk dapat menyelesaikan berbagai tugas, sehingga ia akan sedikit / tidak melakukan perbuatan mencontek. Akbar (2012) mengungkapkan bahwa perilaku mencontek dapat disebabkan karena malas atau tidak belajar, diikuti oleh anggapan bahwa "mencontek untuk mendapatkan nilai yang baik, ketakutan untuk gagal, mencontek adalah suatu yang wajar, tidak mempunyai waktu yang cukup untuk mengerjakan soal, mudah menyerah, menganggap pelajaran yang diujikan tidak penting, cemas dan stress".

\section{METODE}

Penelitian ini menggunakan metode dengan pendekatan kuantitatif yaitu untuk mencari hubungan antar variabel, dengan menggambarkan dan menjelaskan melalui pengumpulan data numerik dari sejumlah sampel yang berisi pernyataan dan tanggapan (Creswell, 2012). Sesuai dengan tujuan penelitian, metode yang digunakan adalah metode analisis jalur (path analysis). Analisis jalur digunakan oleh peneliti dengan tujuan untuk mengetahui dan menguji model hubungan antar variabel yang berbentuk sebab akibat (Sugiyono, 2008). Penelitian ini yang akan dicari adalah pengaruh variabel hardiness (X), terhadap variabel perilaku menconek (Z), melalui variabel efikasi diri (Y). Responden yang terlibat adalah siswa SMA. Karena berdasarkan pendapat Anderman \& Mudrock pada tahun 2007, siswa sekolah menengah atas lebih cenderung melakukan perilaku mencontek dari pada siswa di sekolah dasar. Hasil wawancara yang dilakukan oleh peneliti kepada beberapa guru SMA, terdapat antisipasi yang diberikan oleh tim sekolah agar menghindari dan mengurangi siswa untuk berperilaku mencontek diantaranya alat elektronik dikumpulkan pada saat ujian berlangsung dan ditegur apabila terlihat siswa yang melakukan perilaku mencontek. Namun demikian, masih terdapat siswa yang 
melakukan perilaku mencontek baik dalam mengerjakan tugas sekolah ataupun pada saat ujian sedang berlangsung.

Berdasarkan paparan tersebut, subjek pada penelitian ini adalah siswa di salah satu SMA. Teknik sampling yang digunakan adalah teknik sampling probabilitas, karena setiap anggota populasi akan memiliki kesempatan yang sama untuk dipilih menjadi anggota sampel. Teknik probabilitas yang digunakan adalah teknik simple random sampling, yaitu teknik yang digunakan untuk menentukan partisipan agar dapat dijadikan sampel yang akan mewakili populasi (Creswell, 2012). Teknik random sampling dilakukan dengan pegambilan sampel secara acak melalui pengundian dari siswa di salah satu SMA. Sehingga jumlah sampel ditentukan menggunakan rumus Slovin dengan toleransi eror 5\% sehingga total sampel adalah 319 orang siswa kelas 10 dan 11.

Instrumen yang digunakan adalah hardiness scale dari Creed, Conlon \& Dhaliwal tahun 2013 untuk mengukur kepribadian hardiness, instrumen perilaku mencontek dari Wijaya, S tahun 2016 untuk mengukur perilaku mencontek, dan efikasi diri dari Schwarzel \& Jarusalem, 1995 untuk mengukur efikasi diri siswa.

Instrumen menggunakan skala Likert yang terdiri dari empat pilihan (sangat tidak setuju, tidak setuju, setuju, sangat setuju). Peneliti melakukan uji tryout terlebih dahulu untuk menguji reliabilitas dan validitas instrumen hardiness dan efikasi diri yang sebelumnya dilakukan penilaian ahli kepada tiga ahli di bidang kajian instrumen. Kemudian peneliti menyebarkan kuesioner hardiness dan efikasi diri kepada 402 siswa diluar sampel penelitian. Hasil reliabilitas hardiness sebesar 0, 769; efikasi diri sebesar 0,829; dan untuk perilaku mencontek sebesar 0.80. Uji analisis data menggunakan analisis jalur.

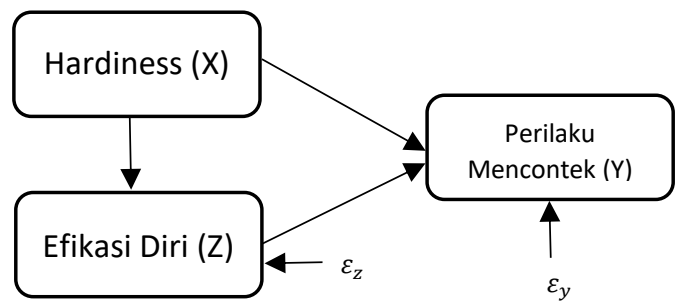

Gambar 1

Model Analisis Jalur Penelitian

Hal utama yang dilakukan pada analisis jalur adalah menentukan diagram jalur. Adanya diagram jalur yang dibuat oleh peneliti bertujuan untuk menggambarkan bahwa $\mathrm{X}$ dapat memilikki pengaruh langsung terhadap $\mathrm{Y}$, di sisi lain $\mathrm{X}$ berpengaruh pada $\mathrm{Z}$ yang 
pada akhirnya berpengaruh terhadap Y (Pedhazur, 1997). Diagram jalur akan menggambarkan bagaimana arah pengaruh yang menjadi fokus penelitian, yang kemudian dilanjutkan dengan analisis menggunakan perhitungan statistik.

Diagram jalur pada gambar 1 terdiri dari tiga variabel, yaitu mencari pengaruh variabel hardiness $(\mathrm{X})$ terhadap variabel perilaku mencontek $(\mathrm{Y})$ melalui variabel efikasi $\operatorname{diri}(\mathrm{Z})$.

\section{HASIL}

Hasil penelitian menunjukkan bahwa kepribadian hardiness berpengaruh signifikan terhadap perilaku mencontek melalui efikasi diri pada siswa SMA, terdapat pengaruh yang signifikan dari kepribadian hardiness terhadap perilaku mencontek secara negatif. Semakin tinggi kepribadian hardiness yang dimiliki siswa maka semakin rendah perilaku mencontek yang dilakukan. Selain itu variabel efikasi diri secara signifikan bisa menjadi variabel mediasi pada pengaruh hardiness terhadap perilaku mencontek pada siswa SMA. Hal tersebut melekat pada diri siswa dalam menghadapi berbagai tugas yang dimiliki.

Koefisien jalur dari variabel kepribadian hardiness terhadap perilaku mencontek sebesar -0,393. Nilai koefisien jalur yang negatif menunjukkan bahwa variabel kepribadian hardiness berpengaruh negatif terhadap perilaku mencontek. Dengan kata lain, semakin tinggi kepribadian hardiness yang dimiliki oleh siswa-siswi maka semakin rendah perilaku mencontek yang dilakukannya. Hasil perhitungan menunjukkan p-value adalah $0,000<0,05$, artinya terdapat pengaruh secara signifikan antara kepribadian hardiness terhadap perilaku mencontek pada siswa SMA. Nilai koefisien determinasi $\left(\mathrm{R}^{2}\right)$ sebesar 0,122 , yang artinya $12,2 \%$ total variasi dari variabel dapat dijelaskan oleh persamaan struktural tersebut. Dengan kata lain, pengaruh hardiness terhadap perilaku mencontek mampu menjelaskan (naik-turunnya) variabel itu sendiri sebesar 12,2\%, sisanya $87,8 \%$ dijelaskan oleh variabel-variabel lain.

Koefisien jalur variabel kepribadian hardiness terhadap efikasi diri adalah sebesar 0,477 . Nilai koefisien jalur yang positif menunjukkan bahwa variabel kepribadian hardiness berpengaruh positif terhadap efikasi diri. Dengan kata lain, semakin tinggi kepribadian hardiness yang dimiliki oleh siswa-siswi maka semakin tinggi efikasi diri yang dimilikinya. Nilai $p$-value adalah 0,000 yang artinya terdapat pengaruh signifikan kepribadian hardiness terhadap efikasi diri pada siswa SMA. Nilai koefisien determinasinya adalah 0,228 yang artinya $22,8 \%$ total variasi dari variabel efikasi diri dapat dijelaskan oleh variabel hardiness, atau pengaruh hardiness terhadap efikasi diri mampu menjelaskan (naik-turunnya) variabel itu sendiri sebesar $22,8 \%$, sisanya $77,2 \%$ dijelaskan oleh variabel-variabel lain. 
Berdasarkan tabel 1 dan Gambar 2, diketahui pengaruh langsung hardiness terhadap efikasi diri adalah 0,48; pengaruh langsung efikasi diri terhadap perilaku mencontek adalah 0,14 dan pengaruh langsung hardiness terhadap perilaku mencontek adalah -0,39.

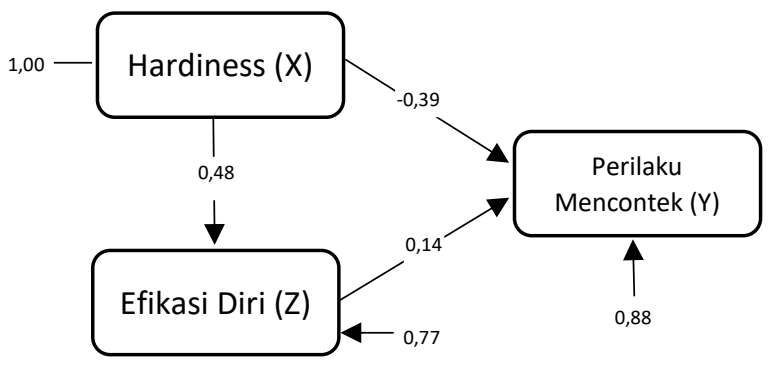

Chi-Square $=0,000, \quad d f=0, \quad P$-value $=1,000, \operatorname{RMSEA}=0,000$

Gambar 2

Koefisien Jalur Pengaruh Hardiness terhadap Perilaku Mencontek Melalui Efikasi Diri

Tabel 1

Koefisien Analisis Jalur

\begin{tabular}{clllc}
\hline \multicolumn{1}{c}{ Efek } & & Path & Koefisien \\
\hline Direct Effect & Hardiness & $\rightarrow$ & Efikasi Diri & 0,48 \\
& Efikasi Diri & $\rightarrow$ & Perilaku Mencontek & 0,14 \\
& Hardiness & $\rightarrow$ & Perilaku Mencontek & $-0,39$ \\
Indirect Effect & Hardiness $\rightarrow$ Efikasi Diri $\rightarrow$ Perilaku Mencontek & $0,48 * 0,14=0,067$ \\
Total Effect & Hardiness $\rightarrow$ Perilaku Mencontek & $-0,39+0,067=0,323$ \\
\hline
\end{tabular}

\section{PEMBAHASAN}

Kepribadian hardiness akan membuat setiap siswa dapat menghadapi berbagai rintangan dan menjadikan kesulitan sebagai tantangan baik kesulitan dalam menyelesaikan tugas-tugas sekolah hingga siswa dapat mampu menyelesaikan segala tugasnya.

Berdasarkan hasil perhitungan penelitian dapat diketahui kepribadian hardiness yang dimiliki oleh siswa-siswi SMA dapat menjadi salah satu pengaruh untuk perilaku mencontek yang dilakukan. Adanya kepribadian hardiness pada siswa akan membuat perilaku mencontek menjadi berkurang bahkan tidak dilakukan. Dahiya dan Sarita (2015) mengungkapkan bahwa perilaku mencontek juga mengenai pandangan yang dihadapi oleh siswa-siswi mengenai akademik dan besarnya stres yang diterima. Siswa cenderung 
melakukan perilaku mencontek ketika memandang bahwa tidak ada cara selain mencontek yang dapat membuat dirinya menjadi lebih dari yang diinginkan. Sehingga stres yang dialami dalam kehidupan sehari-hari tidak lagi dapat teratasi untuk dapat menyelesaikan tugas atau efikasi diri yang dimiliki siswa akan membantu siswa mengerjakan dengan yakin dan menghindari perilaku kecurangan.

Perilaku mencontek dapat terjadi karena faktor demografis, akademik, motivasi, dan karakteristik kepribadian (Anderman \& Mudrock, 2007). Salah satu karakteristik kepribadian itu ialah kepribadian hardiness. Kepribadian hardiness yang dimiliki oleh siswa siswi SMA Laboratorium UPI kota Bandung ini menjadi karakteristik yang ada dalam dirinya bahwa dirinya memandang sebagai siswa yang dapat menghadapi setiap peristiwa, tugas-tugas yang sulit apabila memiliki hardiness yang baik akan dapat menyelesaikan tugas sekolahnya. Siswa dapat melibatkan kontrol diri yang baik, memiliki komitmen, dan menganggap tantangan sebagai kehidupan yang perlu di hadapi sehingga tidak melakukan perilaku mencontek.

Berdasarkan hasil penelitian, bahwa semakin tinggi kepribadian hardiness maka semakin tinggi efikasi diri yang dimiliki oleh siswa, menandakan bahwa siswa-siswi SMA Laboratorium UPI Kota Bandung memiliki keyakinan yang ada dalam dirinya untuk dapat menyelesaikan tugas yang dimiliki, menganggap tantangan adalah peristiwa yang harus dihadapi dan dapat menghindari keadaan penuh tekanan dengan keyakinan yang dimiliki.

Sejalan dengan penelitian yang dilakukan oleh Vinothkumar, Kousalya, \& Rai, pada tahun 2016 bahwa efikasi diri dan kepribadian hardiness secara bersama-sama memiliki korelasi yang positif terhadap prestasi belajar. Efikasi diri membuat siswa memiliki pengalaman yang baik, kekuatan untuk bermimpi, komunikasi dengan tanggapan yang baik, dan memiliki emosi positif dalam menghadapi kecemasan. Hardiness yang dimiliki membuat siswa untuk menghadapi berbagai kehidupan dengan mengurangi situasi stress.

Efikasi diri ini terdiri dari level, strength, dan generality (Bandura; 2009). Hasil penelitian menunjukkan siswa diindikasikan memiliki efikasi diri yang tinggi. Sehingga level yang dimiliki akan dapat memahami seberapa sulit suatu tugas yang diterima dalam kehidupan sehari-hari. Strength membuat siswa memiliki kekuatan penilaian dalam ketahanan dan keuletan untuk menyelesaikan suatu tugas. Generality akan membuat siswa memiliki konsep dirinya tidak hanya untuk keyakinan menyelesaikan tugas namun dapat menjadi efikasi diri dalam hal lainnya selain menyelesaikan tugas.

Artinya variabel efikasi diri secara signifikan bisa menjadi variabel mediasi pada pengaruh hardiness terhadap perilaku mencontek pada siswa SMA. Berdasarkan hasil perhitungan pada tabel 1, dapat disimpulkan terdapat pengaruh efikasi diri sebagai variabel mediasi terhadap perilaku mencontek sebesar 0,067. Selain itu, masing-masing variabel hardiness terhadap perilaku mencontek, hardiness terhadap efikasi diri dan efikasi 
diri terhadap perilaku mencontek memiliki pengaruh yang signifikan. Sehingga keberadaan variabel mediator menjadi parsial mediated. Sejalan dengan penelitian yang dilakukan di Pakistan kepada 15 siswa mengenai efikasi diri terhadap performance belajar siswa, pada penelitian tersebut memiliki hasil bahwa siswa yang memiliki efikasi diri tinggi memperoleh nilai yang lebih tinggi dari siswa yang memiliki efikasi diri rendah, selain itu tanggapan partisipan dalam penelitian tersebut juga menunjukkan bahwa siswa dengan efikasi diri yang tinggi dapat merencanakan dan mempelajari pelajaran yang kompleks di masa mendatang (Ahmad, A; 2013).

Efikasi diri pada siswa SMA menjadi keyakinan yang dimiliki bahwa dirinya bisa menyelesaikan tugas yang diterima baik disekolah atau di luar sekolah. Efikasi diri siswa, pada umumnya membuat siswa lebih terlibat dalam kegiatan kelas, bahkan siswa dengan efikasi diri yang tinggi akan dapat menguasai keterampilan pada tugas-tugas yang dihadapi (Anderman, 2006). Banyaknya tugas tersebut siswa akan cenderung menerima dan menyelesaikannya. Sehingga siswa tersebut akan berharap bahwa dirinya memiliki peran untuk bergabung dalam menyelesaikan suatu tugas yang diterima. Galloway pada tahun 2012 melakukan penelitian mengenai pandangan kecurangan kepada siswa SMA hasilnya siswa memandang bahwa perilaku kecurangan bukan menjadi sebuah fenomena untuk siswa, namun siswa menggambarkan bahwa sekolah sebagai kejelasan untuk bertindak curang atau menghindari kecurangan. Dalam hal ini, keterlibatan kepribadian untuk menilai lingkungan dalam siswa menjadi salah satu bentuk pengaruh lainnya yang dapat mengerahkan siswa dengan perilaku mencontek yang dilakukan.

Berdasarkan penelitian ini, dapat disimpulkan bahwa terdapat pengaruh yang signifikan dari kepribadian hardiness terhadap perilaku mencontek melalui efikasi diri. Artinya kepribadian hardiness yang dimiliki oleh siswa-siswi SMA Laboratorium UPI Kota Bandung memiliki sumbangsih terhadap perilaku-perilaku yang muncul pada saat mengerjakan tugas. Adanya kepribadian hardiness yang kuat dan efikasi diri yang tinggi akan dapat menolong siswa untuk tahan dalam menghadapi berbagai tugas yang dimiliki. Selain itu keyakinan yang ada dalam siswa dapat menolong siswa untuk yakin bahwa sebagai seorang siswa harus menyelesaikan tugas-tugas sekolahnya. Penelitian ini juga mendapati hasil bahwa terdapat pengaruh yang signifikan dan negatif dari kepribadian hardiness terhadap perilaku mencontek. Artinya, semakin tinggi kepribadian hardiness, semakin rendah perilaku mencontek yang dilakukan oleh siswa SMA. Terdapat juga pengaruh yang signifikan dari kepribadian hardiness terhadap efikasi secara positif. Dapat dikatakan semakin tinggi kepribadian hardiness maka siswa akan semakin yakin untuk bisa menyelesaikan tugas-tugas yang dimiliki. 


\section{DAFTAR PUSTAKA}

Akbar, S. R. N. (2012). Profil Mencontek Siswa Sekolah Menengah Atas: Studi Untuk Membuat Layanan Bimbingan Konseling Terhadap Siswa Kelas XI PGRI 1 Kota Bandung Tahun Ajaran 2010/2011. Universitas Pendidikan Indonesia, Bandung.

Anderman, E, M. (2006). Motivational Perspectives on Student Cheating: Toward an Integrated Model of Academic Dishonesty. Educational Psychologist, 41(3), 129-145.

Anderman, E., \& Mudrock, T. (2007). Psychology Of Academic Cheating. San Diego, US: Academic Press.

Bandura, A. (2009). Self-Efficacy in Changing Societies. United States: Cambridge Univesity Press.

Creed, P. A., Conlon, E. G., \& Dhaliwal, K. (2013). Revisiting the Academic Hardiness Scale: Revision and Revalidation. Journal of Career Assessment, 21(4), 537-554. https://doi.org/10.1177/1069072712475285

Creswell, J. W. (2012). Educational Research, Planning, Conducting And Evaluating Quantitative And Qualitative Research. Boston: Pearson.

Dahiya \& Sarita. (2015). Academic Cheating among Students: Pressure of Parents and Teacher. International Journal of Applied Research, 1(10), 793-797.

Eschleman, B. (2010). A Meta-Analytic Examination of Hardiness. International Journal of Stress Management, 17(4), 2770307.

Galloway, MK. (2012). Cheating in Advantaged High Schools: Prevalence, Justifications, and Possibilities for Change. Ethics \& Behavior, 22(5), 378-399).

Hartanto, D. (2012). Bimbingan \& Konseling: Menyontek Mengungkap Akar Masalah dan Solusinya. Jakarta: Indeks.

Kardum, I., Hudek-Knežević, J., \& Krapić, N. (2012). The Structure of Hardiness, its Measurement Invariance across Gender and Relationships with Personality Traits and Mental Health Outcomes. Psychological Topics, 21(3), 487-507.

Kobasa. (1979). Stressful Life Event, Personality, and Health: An Inquiry Into Hardiness. Journal of Personality and Social Psychology, 37(1), 1-11.

Kobasa, S., Maddi, S., \& Khan, S. (1982). Hardiness and Health: A Prospective Study. Journal of Psychology and Social Psychology, 42(1), 168-177.

Kumalasari, N. (2015). Hubungan Antara Efikasi Diri Dengan Perilaku Menyontek. Universitas Muhammadiyah Surakarta. 
Kusmaningtyas, A. R. (2015). Hubungan Kepribadian Hardiness Dengan Kemampuan Regulasi Emosi Perawat Rumah Sakit Di Kota Bandung. Universitas Pendidikan Indonesia, Bandung.

Maddi, S. R. (2006). Hardiness: The Courage to Grow From Stresses. The Journal of Positive Psychology, 1(3), 160-168. https://doi.org/10.1080/17439760600619609

Maddi, S. R. (2013). Personal Hardiness as the Basis for Resilience. Springer Briefs in Psychology, 2, 7-18. https://doi.org/10.1007/978-94-007-5222-1

Maddi, S. R., Harvey, R. H., Khoshaba, D. M., Fazel, M., \& Resurreccion, N. (2009). The Personality Construct of Hardiness, IV. Journal of Humanistic Psychology, 292305. https://doi.org/10.1177/0022167809331860

Pedhazur, E. J. (1997). Multiple Regression In Behavioral Research Explanation And Prediction. United States of America: Wadsworth Thomson Learning.

Schwarzel \& Jarusalem (1995). Efficacy Scale.

Sugiyono. (2008). Statistika untuk Penelitian. Bandung: CV Alfabeta.

Vijayalakshmi, Mohanasundaram, K., \& Ramganesh, E. (2016). Construction and Standardization of Cognitive Hardiness Scale for B.ed. Student-Teachers. Indian Journal Of Applied Research, 6(8), 518-522.

Vinothkumar, M., Kousalya, \& Rai, V. (2016). Moderating Roles of Hardiness and SelfEfficacy in the Relationship between Flow and Academic Procrastination on Academic Performance: A Structural Equation Model Approach. The International Journal of Indian Psychology, 3(November).

Wijaya, S. (2016). Hubungan Antara Kreativitas, Moral Judgment, dan Perilaku Menyontek Pada Siswa Di SMA " $X$ ” Di Kota Bandung. Universitas Pendidikan Indonesia. 